\title{
Concept Analysis of Virtual Mentoring
}

\author{
Susan Clement* \\ South Georgia State College, Associate Professor of Nursing, Georgia
}

*Corresponding author: Susan Clement, South Georgia State College, Associate Professor of Nursing, 100 West College Park, Douglas, 31533, Georgia

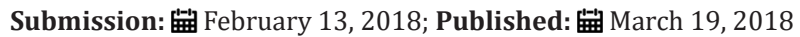

\begin{abstract}
The concept of virtual mentoring is defined and analyzed in relation to its importance in nursing education. The benefits of a mentor and a good mentoring relationship, examples of successful virtual mentoring models, and how and why virtual mentoring is so valuably related to the education of the doctoral nursing student is also discussed. More doctoral prepared nursing educators will create effective teachers and nurse leaders, helping to reduce the nursing shortage and fill the gaps in the primary healthcare system. Virtual mentoring may strengthen the nursing profession by providing an opportunity for higher education where time restraints and geographical boundaries are no longer a restricting issue.
\end{abstract}

The traditional face-to-face mentoring has been commonly utilized by the nursing profession as a strategy to prepare nurses for practice in a variety of settings [1] but there is a new species on the horizon, virtual mentoring. Technology-mediated mentoring is a relatively new phenomenon in the field of nursing and is rapidly becoming a vital component in the current trend of online education. With the advancement of technology in education, there is a need for a newly designed concept of mentoring that may provide an opportunity to expand the resources and capabilities of doctoral prepared nurse educators. The purpose of this paper is to explore and define the concept of virtual mentoring and the impact it may have on nursing education.

In order to establish a functional model for virtual mentoring, an understanding of the terminology "virtual mentoring" must first be analyzed and defined. Merriam-Webster's [2] online dictionary defines the term mentor as "someone who teaches or gives help and advice to a less experienced and often younger person", whereas the term virtual is defined as "existing or occurring on computers or on the internet". The concept of mentoring dates all the way back to Greek mythology arising from Homer's The Odyssey character Mentor, who was thought of as a trusted adviser, teacher, and wise counselor [3]. Vinales [4] defines mentoring as: "A process by which one person (the mentor) encourages another individual (mentee) to manage his or her own learning so that the mentee becomes self-reliant in the acquisition of new knowledge, skills, abilities and develops a continuous motivation to do so". The term virtual mentoring has been used interchangeably with the terms E-mentoring, online mentoring, telementoring and cybermentoring [5]. Virtual mentoring, "e-mentoring" was described as "a computer mediated, mutually beneficial relationship between a mentor and a protégé which provides learning, advising, encouraging, promoting, and modeling that is often boundary less, egalitarian, and qualitatively different than traditional face-to-face mentoring" [6]. "Virtual mentoring" simply refers to any mentoring activity that does not take place face-to-face [7].

Virtual mentoring may provide students and educators opportunities for learning that may not have been previously available due to location and mentor availability. Mentors play a vital role in the education of nursing students; and with today's technology there is a suite of communication tools that help to burst the virtual world wide open, providing mentoring to people working in remote locations, anyone, anytime, who would not otherwise have access to a mentor [8]. While virtual mentoring is a relatively new concept to the field of nursing, companies like IBM, Xerox, and HP have been using the concept of virtual mentoring to establish global contacts [9].

Virtual mentoring may prove to be an invaluable asset to the field of nursing and can be a considerable educational tool. Access to a mentor without geographical boundaries and time restraints would have an enormous impact on the educational growth and advancement of the doctoral nursing student. Advanced technology and internet based communication such as email, social networking, and chat rooms are providing a new perspective on the existing concept of mentoring. The mentor-mentee relationship should include the use of technology, fostering dialogue through multiple modes of communication, all while creating a positive outcome for both mentors and students [10]. Virtual mentoring is one of many new advancements in technology contributing to the development of on-line educational programs and the professional workplace.

\section{Review of Literature}

A GALILEO search was conducted browsing by subject; the search topics used were: mentor, mentoring, virtual mentoring, online mentoring, e-mentoring, nursing, education, \& doctoral student. A Google scholar search of the World Wide Web was also conducted using the same search topics. Articles chosen were limited to full text articles from scholarly peer reviewed journals with publication dates between 2010 and 2016, with the exception of a few older but relevant materials. In the review of literature the focus will be on the value of mentoring, examples of successful mentoring through the use of technology, "virtual mentoring", and why the exploration of virtual mentoring in nursing education of the doctoral student can and must be put in to place for the benefit of all.

During the review of literature, many authors listed defining characteristics of a mentor and the act of mentorship on the mentor-mentee relationship. The concept of mentorship has been central to nursing education since the 1980s [3]. Holley \& Caldwell 
[11] emphasized the significance of mentoring, explaining, "The cultivation of developmental or mentoring relationships between graduate students and their professors is a critical factor in determining the successful completion of graduate programs". Doctoral students are more likely to persist to graduation and report higher degrees of satisfaction with their program when they engage in a meaningful relationship with a faculty mentor or advisor [11]. Mijares [10] states mentoring consists of advising, coaching, counseling, guiding, sponsoring, teaching, role modeling, and resource facilitating; a partnership which assist the mentee to obtain competence all while providing academic and emotional support.

Mijares [10] also describe mentoring as a process involving trust, open communication, goal-setting, respect, and caring. Mentoring is an interpersonal relationship of two individuals at different stages in their career; where a more experienced person develops a relationship with a less experienced person to increase the chances of career success [12]. Mentoring helps to instill confidence and self-esteem in the protégé by increasing motivation levels, career development, the development of leadership skills, greater awareness of skills and a reduction in work-related stress [12]. Mentoring relationships are seen as supportive if not necessary for successful career development in that mentors expand professional networks as protégés become tomorrow's leaders [12].

Not only is a virtual mentoring experience beneficial for the mentee or student, but was also proven to be quite the learning experience for the mentor as well. For mentors, the mentoring relationship seems to aid in developing leadership skills, extending professional influence, and stimulation thinking and research [12]. In the article by Williams [6], e-mentors reported personal satisfaction from sharing knowledge and experience, and working with students. They felt the function of a mentor was not to tell the protégé what to do, nor was it to give orders or directives, but rather to present possibilities and to advise on possible outcomes [6].

Online collaborative mentoring was found to have tremendous potential when successfully aligned with the dynamics of (online) learning communities, and characterized by supportive interpersonal relationships, collegiality, constructive feedback and authentic learning, all of which serve to enhance a teachers' professional growth [13]. Mentors also reported improved technical knowledge, greater depth of understanding, and strengthened knowledge of concepts; proving that mentoring is an effective tool to develop skills for both mentor and mentee [10]. Throughout the mentoring literature, experts point to the benefits that mentoring provides with regard to professional identity development and that these benefits are largely bidirectional in that they provide both mentor and mentee with professional advantages [12].

There is no doubt that the act of mentoring is a valued asset; but can it be as beneficial in the virtual world when compared to the traditional face-to-face approach. During my literature review, it was interesting to find that virtual mentoring is not a totally new concept within the educational arena. The concept, first appeared in 1999 when a program was started at the Saskatchewan Valley School Division [14]. This program was initiated in order to establish the use of computers and internet technology in eighteen local schools through the use of virtual mentoring of new and existing faculty. While the project did not proceed as initially planned, many lessons about the advantages and limitations of virtual mentoring were learned. Limitations included lack of promised technical equipment and support, as well as determining the need for at least one face-to face meeting. Advantages included many time saving techniques for both the mentee and the mentor. Other mentoring models were those mentioned by Dorner \& Kumar [13], Williams [6] \& Thompson [5].

Dorner \& Kumar (2016) present the Mentored Innovation Model, an online collaborative mentoring model using a combination of an online modular approach of formal pedagogical Internet and Communication Technologies (ICT) training with an informal online community experience of sharing, developing and critiquing of shared learning resources. Williams [6] describes satisfactory outcomes of a virtual mentoring scheme used as a functional component within an online graduate course. The course was designed using an e-mentoring component to provide guidance and assistance to the distanced students and then evaluated by third party researchers [6]. The researchers reported mutual benefits for both the mentor and mentee including gained technological skills, professional assessment, social benefits, and personal satisfaction [6]. Thompson et al. [5] explored the viability and effectiveness of virtual mentoring for an e-learning module development within arts and humanities. It was concluded that e-mentoring is a promising socio-technical solution to the logistical constraints of the traditional face-to-face classroom. Many of the empirical referents that apply to mentoring can also be incorporated into the virtual mentoring setting. These include providing a structured learning environment for building confidence, sharing learned experiences, guidance and support from a role model, all while linking theory to practice and providing constructive and honest feedback.

The literature has proven that virtual mentoring is beneficial at fulfilling educational needs; but how do we utilize it in the world of nursing for higher education. The rest of the literature review will illustrate why the integration of virtual mentoring, in reference to the doctoral nursing student, is so important. In 2010, the Institute of Medicine (IOM) called for nurses to seek higher levels of education and to be educated in new ways $[15,16]$. This report recommended the need to double the number of nurses with a doctorate by 2020 , currently at the time of the report in 2010 less than $1 \%$ of nurses held a doctoral degree $[15,16]$. The nursing faculty shortage is well documented [16] and it is clear that education of nurses needs to be provided at an advanced level with the focus on global strategies to enhance the quality and resources for doctoral education in nursing [17].

The landscape of doctoral education in nursing is rapidly changing; more doctoral prepared nurses are needed to prepare the nursing labor force for delivery of healthcare services, helping 
to reduce the nursing shortage [16]. The objectives should be to strengthen the resources and infrastructure of doctoral education in nursing and to increase the number of doctoral supervisors and students [17]. This is where the need to rethink the traditional face-to-face faculty model and employ more innovative technology based structures come in to play.

Goodfellow [15] describes a 2-year pilot project of a distant faculty model for a school of nursing where communication mainly included e-mail, conference calls, and the use of virtual voice communication tools, Skype and other Internet services that offer voice and visuals in real time. Distance education models offer a new way to reach nurses who may otherwise not have the opportunity to attend graduate school because of barriers posed by geographical location or employer and family demands [15]. With the onset of advanced technology, distant education models are increasingly present in schools of nursing [15]. Not only was virtual mentoring beneficial in this distant faculty model but also proven to be successful as evidenced by three doctoral students successfully defending their dissertation proposals [15].

The mentoring relationship between graduate students and their professors is a critical factor in determining the successful completion of their graduate program [11]. Mentoring plays an important role in graduate student development as mentored students demonstrate more confidence in their communication abilities and their professional identities and report being more Table 1 connected in professional networks [12]. Mentoring within academic settings aids the student in areas of networking and professional identity development by helping them develop goals and a sense of direction (Murdock et al., 2013). Mentoring in academia can assist students to complete their program and promote retention of faculty [10]. Murdock [10] also found that doctoral students who received mentoring from faculty members experienced encouragement and support to engage in professional development opportunities such as presenting at workshops and attending conferences. Doctoral training provides students with the ability to think critically, identify the gaps in knowledge, search for truth without prejudice, take risks with ideas, be creative and imaginative in solving problems and communicate clearly and effectively [17].

Virtual mentoring suits busy time schedules and accommodates distance locations providing options to overcoming barriers while presenting lower cost and increased flexibility as it is free from time and place constraints [6]. In spite of the widespread use of mentoring, the concept of virtual mentoring is under investigation for its use in the field of graduate nursing education (Table 1). By establishing a continuous interaction among educators and students, the use of virtual mentoring may create a lifelong learning environment. Supporting doctoral students involves intensive mentoring through an online supervisor-student relationship, facilitating purposeful, structured coursework [18].

\begin{tabular}{|c|c|c|}
\hline \multicolumn{2}{|c|}{ Antecedents, Criteria and Consequences of Virtual Mentoring } \\
\hline Antecedents & Criteria & Consequences \\
\hline Motivation & Responsibility for the learning process & Maximized learning \\
\hline Commitment & Reciprocal relationship & Promotion of personal and professional growth \\
\hline Educated mentor; less experienced student & Knowledge differential & Flexible schedule \\
\hline Internet/electronic access & Freedom of time and location & \\
\hline
\end{tabular}

\section{Criteria}

To summarize the literature on virtual mentoring, there are four common themes that characterize mentoring. As noted in Table 1 above, the first attribute mentioned is a teaching and learning strategy where in both the mentor and mentee take responsibility for the learning process. The second attribute is that a reciprocal relationship between the mentor and mentee must be present. The third attribute is that there is generally a knowledge differential between the mentor and mentee in order to enhance the learning environment. The fourth attribute deals with time and location, the beauty of virtual mentoring is that it can take place almost anytime, anywhere regardless of the location of the mentor and mentee. The major criteria for virtual mentoring include internet access and a general understanding of the technology. Understanding the use of technology and having access to the internet are themes repeated in several research studies $[6,13,14]$. Criteria for virtual mentoring consists of a reciprocal relationship conducted at a distance, involving regular contact, a trusting relationship, and having in place mutual goals to be obtained $[5,6]$.

\section{Cases}

\section{Model case}

Lisa, a doctoral prepared instructor is planning on implementing an online trends and issues course for incoming doctoral nursing students. The learning activities for the course include online discussion postings, asynchronous group discussions, and working with an online mentor. The instructor has involved the technology department of the university in order to establish the technological needs for the course and also holds a personal degree in computer technology.

Lisa prepares the syllabus, the objectives, the assignments, and the grading tool for the course content in the distance learning program at the university. The students meet for the first time in a face-to-face orientation setting to provide a clear understanding of the expectations of the course, an opportunity to meet the mentor, and a demonstration of the technology necessary for a distance learning course. All ancillary university staff is present including the technology team, the librarian, and the financial aid advisor. 
Students are given the opportunity to ask questions and use the current technology required for this course.

The online course is implemented and students are provided with the mentors contact information. A regular schedule for meeting is established between the mentor and mentee. Google Plus was the chosen form of communication between the mentor and mentee. Follow ups are made at predetermined intervals to make sure that the student is staying on task. These follow ups are in the form of telephone calls, emails, and Google hangouts. Within one semester, all of the doctoral students have Google Plus accounts and communicate on a regular basis with their mentors.

\section{Contrary case}

An online course has recently been implemented at a local college. Students are very interested in taking a course online. The professor teaching the course has never taught an online course before, but needs the extra income so agrees to teach the course.

On the first day of class, the instructor does not know how to use the computer program and fails to contact the technology department to help create the course in the provided online media The instructor informs the students she will provide no feedback in the form of assistance or mentoring in the form of technology and they should find a mentor at the technology department at the university to help them with any course issues. Students are calling for instructions on how to prepare for the class, what textbooks are needed, and general course information. The instructor does not know how to start implementing this course online and provides no virtual mentoring to assist the students with their questions or issues.

\section{Related case}

A related concept to virtual mentoring is telemedicine. Telemedicine addresses the concept of technology based sharing of information. The physician examines the patient with the use of computer technology without actually having to be at the patient's bedside. This type of technology establishes an interaction between physician and patient that ordinarily may not have occurred. Virtual mentoring is a form of communication that can be used with telemedicine. Telemedicine with the use of technology can be utilized by perinatologists from metropolitan cities performing ultrasounds on high risk obstetric patients from rural areas that do not have access to advanced medical attention.

\section{Borderline case}

An educational course that is delivered in a hybrid format is an example of a borderline case for virtual mentoring. An online course has been developed and mentors are established. The course is implemented in an online fashion only fifty percent of the time. Students are expected to attend a traditional classroom type setting for the remaining fifty percent. The students will then have the opportunity to meet face-to-face with their mentors as well as online. The use of technology and online mentoring is the prime focus of initiating virtual mentoring, but the college felt the students still need the face-to-face interaction with the instructors.
The instructor offers two days only two days a week for hangouts or discussion forums.

\section{Measurement of Concept}

Virtual mentoring is being explored in many settings, with those involved expressing positive outcomes. In the review of literature, Dorner \& Kumar [13]; Williams [6]; and Thompson [5], all gave examples of successful mentoring models that incorporated technology. It is well known that mentoring is a valued asset to the learning environment and when the mentorship can be offered online through virtual mentoring, it makes the process an even more desirable one. With virtual mentoring, the mentor and mentee both have the convenience of meeting in a nonstructured environment. Virtual mentoring can take place from the luxury of one's home, office, car, or even their child's little league ball field. Most pursuers of doctoral degrees are working parents, so convenience and flexibility are a must to ensure a successful endeavor. As stated earlier, the IOM has declared the need for more doctoral prepared nurses by the year 2020. This date is fast approaching and the more accessible higher education is to the doctoral nursing student, the more eager applicants universities will see. In the study by Lach [19] an on-line survey was utilized focusing on nurses who had experienced distance mentoring as a mentee. The survey was conducted using ESP Easy Survey Package, a shareware program for developing on-line questionnaires [19]. The mentoring survey included thirty-three multiple-choice, short-answer, and open ended questions focusing on the details regarding the distance mentoring experience. This study concluded that distance mentoring had a positive impact on the students who participated.

\section{Antecedents}

Antecedent conditions to virtual mentoring are circumstances that are present prior to the initiation of the virtual mentoring program. As identified in Table 1, there were four criteria associated with virtual mentoring and related antecedents. The literature review revealed antecedents for virtual mentoring as motivation, commitment, educated mentor and a less experienced student, and internet or electronic access. The mentor and doctoral student must share a voluntary and reciprocal relationship for mentoring to occur [10]. The mentor is a knowledgeable individual who is willing to share wisdom and experience, and the doctoral student must want the mentor's guidance and support [10]. The primary form of communication between the mentor and doctoral students is electronic, so internet access is a must for virtual mentoring to take place. Job satisfaction and organizational commitment are also linked as antecedents to the concept of virtual mentoring [20].

\section{Consequences}

Consequences condensed from the literature review are listed in Table 1. The significant outcomes or consequences of virtual mentoring are increased self-confidence, maximized learning, promotion of personal and professional growth, and flexibility. Increased self-confidence and a maximized learning environment is accomplished through the combination of teaching, coaching, 
role-modeling and shared experiences [10]. With the utilization of the mentioned outcomes and consequences mentors may enhance the learner's ability to succeed in future professional endeavors. Virtual mentoring can suit busy time schedules and accommodate distanced locations [6]. Virtual mentoring presents increased flexibility because it is free from time and place constraints [6]. A virtual mentoring program can provide access to students all over the world providing a global perspective of nursing education for the doctoral nursing student.

\section{Empirical Referents}

Since virtual mentoring is a relatively new concept in nursing education there are no classes or categories of empirical referents. Empirical referents demonstrate the existence of a concept. Selfreport has been the most commonly used referent for mentoring in nursing. Some empirical referents associated with virtual mentoring include trustworthiness, amount of time allocated for virtual mentoring experience, comfort level of experience reported by both mentor and mentee, and the ability to provide emotional and moral support. Attributes of the concept are observable and measureable, but no one instrument exists to measure the concept of virtual mentoring. Grossman [21] acknowledges that there is not an established formal evaluation procedure in most mentoring relationships unless one counts evaluating the mutually drawn up objectives by the mentor and mentee.

\section{Operational Definition}

Virtual mentoring is defined as "a computer mediated, mutually beneficial relationship between a mentor and a protégé which provides learning, advising, encouraging, promoting, and modeling that is often boundary less, egalitarian, and qualitatively different than traditional face-to-face mentoring" [6].

Virtual mentoring for the doctoral nursing student can be described as a teaching-learning process assisted by technology that is acquired through a reciprocal, career developing relationship between two individuals diverse in professional status and credentials. Obtaining a successful educational experience that transfers to career advancement is the ultimate goal of this process and it is achieved with the use of advanced technology, active student and faculty partnership, and planning and implementing strategies that will enhance the virtual mentoring program. Tools utilized in providing a positive learning outcome for virtual mentoring include telephone calls, emails, and electronic media. Utilizing a mixed method for the research design will enable the researcher to not only have statistical data, but also provide actual lived experiences from the students participating in the study.

\section{Conclusion}

By studying virtual mentoring and exploring the possibilities of the use of virtual mentoring in higher education, instructors from many areas of nursing can capitalize on the unique opportunity for promoting a positive learning experience and a conducive learning environment. It is still a new concept under investigation with limited available resources in the review of literature. Conducting a concept analysis of virtual mentoring and clarifying the attributes, antecedents, consequences, and empirical referents of the term are simply contributions to the future of theory, research, and practice.

As stated earlier in the review of literature, an exploration of the concept, virtual mentoring, may also play a major role in reducing the nursing shortage by establishing a greater pool of doctoral prepared nursing instructors to educate more nurses for the healthcare field. Future research should focus on the most effective mentoring methods to optimize outcomes; this will help delineate how mentoring can be used to maximize learning, increase confidence, and improve competency of students, new professionals and seasoned workers in varied disciplines [10,22]. Virtual mentoring just may be viewed as a more effective method of mentoring for the doctoral nursing student by providing a positive learning environment free of time and location constraints.

\section{References}

1. Eller L, Lev E, Feurer A (2014) Key components of an effective mentoring relationship: A qualitative study. Nurse Educ Today 34(5): 815-820.

2. Merriam-Webster's online dictionary.

3. Fulton J (2015) The archaeology and genealogy of mentorship in English nursing. Nursing Inquiry 22(1): 39-49.

4. Vinales JJ (2015) Mentorship part 1: the role in the learning environment. Br J Nurs 24(1): 50-53.

5. Thompson L, Jeffrie M, Topping K (2010) E mentoring for e-learning development. Innovations in Education \& Teaching International 47(3): 305-315.

6. Williams S, Sunderman J, Kim J (2012) E-mentoring in an Online Course: Benefits and Challenges to E-mentors. International Journal Of Evidence Based Coaching \& Mentoring 10(1): 109-123.

7. Zey M (2011) Virtual mentoring: the challenges and opportunities of electronically medicated formal mentor programs. Review of Business Research 11(4): 141-152.

8. Houck Christiana (2011) Multigenerational and virtual: how do we build a mentoring program for today's workforce? Performance Improvement $50(2): 25-30$

9. Janasz S (2011) Developmental relationships that defy time and place.

10. Mijares L, Baxley SM, Bond ML (2013) Mentoring: A Concept Analysis. Journal of Theory Construction \& Testing 17(1): 23-28.

11. Holley K, Caldwell M (2012) The Challenges of Designing and Implementing a Doctoral Students Mentoring Program. Innovative Higher Education 37(3): 243-253.

12. Murdock JL, Stipanovic N, Lucas K (2013) Fostering connections between graduate students and strengthening professional identity through comentoring. British Journal Of Guidance \& Counselling 41(5): 487-503.

13. Dorner H, Kumar S (2016) Online Collaborative Mentoring for Technology Integration in Pre-Service Teacher Education. Linking Research \& Practice To Improve Learning 60(1): 48-55.

14. Hansen C (2000) Virtual mentoring: A real-world case study.

15. Goodfellow LM, Zungolo E, Lockhart JS, Turk M, Dean B (2014) Successes and Challenges of a Distant Faculty Model. Nursing Forum 49(4): 288297.

16. Smeltzer SC, Sharts Hopko NC, Cantrell MA, Heverly MA, Nthenge S, et al. (2015) A Profile of US Nursing FAculty in Reasearch and Practice Focused Doctoral Education. J Nurs Scholarsh 47(2): 178-185. 
17. McKenna H, Keeney S, Kim MJ, Park CG (2014) Quality of doctoral nursing education in the United Kingdom: exploring the views of doctoral students and staff based on a cross-sectional questionnaire survey. J Adv Nurs 70(7): 1639-1652.

18. Kumar S, Antonenko P (2014) Connecting practice, theory and method: Supporting professional doctoral students in developing conceptual frameworks. Techtrends: Linking Research \& Practice To Improve Learning 58(4): 54-61.

19. Lach H, Pomeroy S, Resnick B, Buckwalter K (2013) The challenges and benefits of distance mentoring. Journal of Professional Nursing 29(1): 39-78.

20. Hartmann N, Rutherford B, Feinberg R, Anderson J (2014) Antecedents of mentoring: Do multi-faceted job satisfaction and affective organizational commitment matter? Journal of Business Research 67(9): 2039-2044.

21. Grossman S (2013) Mentoring in nursing: A dynamic and collaborative process. Springer Publishing, New York.

22. Fox K (2010) Mentor program boosts new nurses' satisfaction and lowers turnover rate. J Contin Educ Nurs 41(7): 311-316.
Creative Commons Attribution 4.0

International License

For possible submissions Click Here



\section{COJ Nursing \& Healthcare}

Benefits of Publishing with us

- High-level peer review and editorial services

- Freely accessible online immediately upon publication

- Authors retain the copyright to their work

- Licensing it under a Creative Commons license

- Visibility through different online platforms 